\title{
User perspectives on Implanon NXT in South Africa: A survey of 12 public-sector facilities
}

\author{
D Pillay, ${ }^{1} \mathrm{MPH} ; \mathrm{M}$ F Chersich, ${ }^{1} \mathrm{MB}$ BCh, PhD; C Morroni, ${ }^{1,2,3,4} \mathrm{MB}$ ChB, DFSRH, DTM\&H, MPH, MSc, PhD; M Pleaner, ${ }^{1} \mathrm{MEd}$; \\ O A Adeagbo, ${ }^{1} \mathrm{MA}$, PhD; N Naidoo, ${ }^{1} \mathrm{MPH} ; \mathbf{S}$ Mullick, ${ }^{1} \mathrm{MB} \mathrm{ChB}, \mathrm{MSc}, \mathrm{MPH}, \mathrm{PhD} ; \mathrm{H}$ Rees, ${ }^{1} \mathrm{MB}$ BChir, MA (Cantab), MRCGP, DCH, DRCOG \\ ${ }^{1}$ Wits Reproductive Health and HIV Institute, Faculty of Health Sciences, University of the Witwatersrand, Johannesburg, South Africa \\ ${ }^{2}$ Women's Health Research Unit, School of Public Health and Family Medicine, Faculty of Health Sciences, University of Cape Town, South Africa \\ ${ }^{3}$ EGA Institute for Women's Health and Institute for Global Health, University College London, UK \\ ${ }^{4}$ The Botswana-UPenn Partnership, Gaborone, Botswana
}

Corresponding author: D Pillay (dianthapillay@gmail.com)

Background. Implanon NXT, a long-acting reversible contraceptive, was introduced in South Africa (SA) in early 2014, aiming to expand the method mix and increase its effectiveness. Initial uptake was high, but has since declined considerably. In these early years after the implant's introduction, it is important to identify reasons for the decline, and remedy gaps in services.

Objectives. To determine periods of use, reasons for the use and early removal of the implant Implanon NXT.

Methods. In 2016, we recruited 152 women from six clinics in the City of Johannesburg, and six in North West Province, SA. A semistructured interview was administered to 91 women currently using the implant and 61 previous users. We examined user perspectives, factors influencing women's experiences with the implant and reasons for discontinuation.

Results. The participants' mean age was 30 years, with only $15 \%$ aged $<25$. Implant uptake was motivated by convenience (less frequent visits required than for short-acting methods) and by favourable views of the method among friends, family and healthcare providers. Only about a quarter of women recalled being counselled pre-insertion about implant effectiveness, and half about side-effects pre-insertion. Among discontinuers, the median time to device removal was 8 months (interquartile range 6 - 12), and this was primarily as a result of sideeffects (90\%), especially bleeding-pattern changes and headaches. Removals were most common among married and cohabiting women, often ascribed to the effects of bleeding on their sexual relationships. Rumours and misinformation contributed to some removals. Overall, women's experiences with the implant were rated 'good' or 'very good' by $74 \%$ of those continuing use, many of whom reported not having experienced any side-effects or that these had diminished over time.

Conclusion. Levels of acceptability among continuing users were high, mainly linked to the method's convenience. While early favourable views drove uptake, negative perceptions, if unaddressed, may now undermine services. Deficiencies in counselling around effectiveness and side-effects may extend to contraceptive services more generally. Women require more intensive support when experiencing sideeffects, including effective systematic approaches to ameliorating bleeding and headaches. Implant services could specifically target young women and first-time contraceptive users. These actions together could reverse the persistent decline in implant use in SA.

S Afr Med J 2017;107(10):815-821. DOI:10.7196/SAMJ.2017.v107i10.12833

Implanon NXT, a single-rod subdermal contraceptive implant, is one of the most effective contraceptive methods available. ${ }^{[1]}$ As a longacting reversible contraceptive (LARC), it is not dependent on user adherence for effectiveness. ${ }^{[2]}$ High levels of uptake and acceptability have been reported worldwide. ${ }^{[3,4]}$ The implant was introduced into the South African (SA) national contraception programme in early 2014, aiming to expand the contraceptive method mix and increase access to LARCs. ${ }^{[5]}$ In the Demographic and Health Survey 2016, about $4 \%$ of sexually active women in the country were using the implant. ${ }^{[6]}$

As with the introduction of any new contraceptive method into a national programme, it is critical to evaluate the experiences and perspectives of users in the early years after its introduction. ${ }^{[7]}$ This evaluation was especially pressing given mounting concerns in the media and among healthcare providers in SA around the performance of implant services and declines in uptake. ${ }^{[8]}$ Using a mixed-methods approach, we conducted a survey of implant users in two districts of SA. This study, one component of a larger evaluation of the implant programme, sought to identify shortcomings in the current services, and the steps required to improve users' experiences.

\section{Methods}

\section{Participant recruitment}

We selected 12 primary healthcare facilities providing contraceptive services: six in the City of Johannesburg, Gauteng Province, and six in North West Province. The methods used to select the facilities and the results of other components of the evaluation have been detailed elsewhere. ${ }^{[9,10]}$ We extracted contact details of women aged $>18$ years who had had an implant inserted since $2014(n=751)$. In total, 262 of these women agreed to be interviewed, with the remainder either not contactable (telephone number not recorded or invalid), or not willing to participate. Owing to difficulties in finding a mutually convenient time for interview, or because a woman did not attend a scheduled appointment, only 152 of these women were interviewed ( $20 \%$ of the potentially eligible 751 ). A fieldworker conducted semistructured interviews face-to-face between June and November 2016. The interviews were held at the facility where the woman had had the implant inserted (Gauteng $n=93$, North West $n=59$ ).

The study was approved by the University of the Witwatersrand Human Research Ethics Committee (ref. no. M151147), and permission for the study was granted by the District Research 
Committee of the City of Johannesburg (ref. no. 2015-16/048), and provincial ethics committee of the North West Province Department of Health (ref. no. NW_2015RP29_838). All participants provided written informed consent, and were reimbursed ZAR50 ( USD4) for their transport expenses.

\section{Study tools and data analysis}

We collected data on women's sociodemographic, reproductive and contraceptive history, motivations for implant use, partner negotiation around use, counselling received, duration of implant use and experiences with the method. Women were asked if they knew how the implant works to prevent pregnancy, and for how long the implant could be used. Those who had removed the implant were questioned about the timing of the removal, reasons for discontinuing the method and subsequent contraception use. Overall experiences of the implant were assessed using a 5-point Likert scale ranging from 'very bad' to 'very good', and by asking women whether they thought the implant was better or worse than a range of other contraceptive methods. Women were asked several open-ended questions, enabling them to narrate their experiences in their own words. For example, women were requested to explain the rating they had given when they had scored the implant on the Likert scale. Data collectors captured women's free text responses on the questionnaire. In some instances, a categorical variable was derived by categorising the free-text responses based on common themes identified in the text.

In our analysis, we sought to describe women's experiences and to contrast the perspectives of women who had continued implant use ('users') with those who had removed it ('removers'), drawing on a World Health Organization analytical framework. ${ }^{[1]]}$ To determine whether the characteristics and perspectives of users and removers differed, we used $\chi^{2}$ tests to compare categorical variables, and Student's $t$-tests or Wilcoxon rank sum tests for continuous variables, as appropriate. We then examined the full text responses, and used them to contextualise and interpret the quantitative data. Participant quotes were selected to illustrate key findings.

\section{Results}

Users $(n=91)$ had inserted the implant a median 24 months ago, while removers $(n=61)$ had used the implant for a median 8 months, with $60 \%$ removing the implant less than a year after insertion. Only $33 \%$ $(20 / 61)$ removed the implant at the same facility where it had been inserted. Sixteen percent (10/61) of removals were performed by a doctor in the private sector.

\section{Sociodemographic characteristics and contraceptive history}

The mean age of both groups was 30 years (Table 1), with 15\% $(23 / 152)$ between ages 18 and 25 . About $80 \%$ were SA citizens, with the remainder mostly from neighbouring Zimbabwe (14\%). Around 60\% of the women were employed, two-thirds ( $66 \%$ user, $67 \%$ remover) had completed secondary schooling and a further quarter (29\% user, $26 \%$ remover) had some form of tertiary qualification. Half of the women (74/148) said they did not know their HIV status, and this was similar in both groups.

While many characteristics of users and removers were similar, some important differences were noted. Removers were much more likely to be currently sexually active than users $(92 \%$ v. $80 \% ; p=0.06)$. Compared with users, removers were more likely to live with their partners $(22 \% \mathrm{v}$. $46 \% ; p=0.002$ ), and to be married ( $34 \%$ v. $22 \%$; $p=0.05$ ).

In both groups, for $13 \%$ of women, the implant was the first contraceptive method that they had used, aside from condoms. Previous use of an intrauterine device (IUD), another LARC, was negligible among all women, and only $28 \%$ of healthcare providers mentioned this as an option for women post-removal, only two of whom took up the offer. At the time of interview, 77\% of the removers were using another contraceptive, mainly depot medroxyprogesterone acetate (DMPA) $(36 \%)$ or the oral pill $(26 \%)$. Male condoms were being used by $38 \%$ of removers (23/61), half of whom were using condoms as their sole contraceptive (11/23).

\section{Factors influencing implant uptake}

The majority (55\%) of participants had first heard about the implant by word of mouth from friends, family and other implant users (Table 2). One woman explained how a family member had influenced her decisionmaking: 'I was interested on it when my younger sister told me about it.' Friends had also helped assuage women's fears about the method: 'At first I was scared that they gonna put something in my arm, but my friend told me it was not painful, so I went for it.' One 18-year old stated that her mother had made the decision: 'I didn't decide to use it, my mom said I must use it, she accompanied me to the clinic'.

About $90 \%$ each of users and removers said that they had themselves gone to the clinic to request that the implant be inserted, rather than the method being suggested to them by a provider during a routine visit. About a quarter of women (30\% user, $25 \%$ remover) had, however, previously heard of the method from a provider, who in some instances appeared to have swayed women's choices: 'The nurses kept teaching us about it and recommending it, so that's why I tried it.' Of note is that only $7 \%(11 / 152)$ of women mentioned publicity materials at clinics or schools, or on the internet and television, as sources of information, although one participant did say that she had heard of the implant 'from the television; Dr Motsoaledi [the minister of health] was explaining about it'.

The primary motivation for choosing the implant was convenience, because the long duration of pregnancy protection meant that frequent clinic visits were not required and women would not have to remember daily pill-taking ( $46 \%$ of users and $67 \%$ of removers; $p=0.03$ ). Reducing the number of visits was especially important for some women. One, aged 24 , stated that she used the implant 'because of the duration that it stays, [I have] enough time to complete my studies'. Similarly, another mentioned that 'I just started working at that time [when the implant was inserted], so I couldn't afford to get leave days [for attending the clinic]'.

Overall, only $11 \%$ of users and $3 \%$ of removers mentioned contraceptive effectiveness as the main motivation for use $(p=0.08)$. One of these, a 19-year-old HIV-positive woman, recounted that 'My mom said I must use it as I was sexual active, she thought it will be a good solution to prevent pregnancy'. Another 33-year-old user also explained: 'I decided on implant because I didn't want to have unwanted pregnancy and the previous injection did not treat me well.' As this suggests, use of the implant in some instances had been driven by dissatisfaction with other methods. Another respondent said: 'The nurse told me about the method 'cos I was complaining about the Pill and how it made me feel.

\section{Women's knowledge about the implant}

Almost all the women knew that the implant could be used for 3 years (99\%). In the free-text responses it was clear that counselling had strongly emphasised the notion that the implant 'needs to' or 'should' be used for that length of time. Many women, however, wondered whether the method was suitable for shorter time periods, for example, if they desired contraception for only 6 months.

Seemingly, little information had been provided to participants about the effectiveness of the implant in preventing pregnancy. Only $29 \%$ of users and $20 \%$ of removers recalled this being discussed 


\begin{tabular}{|c|c|c|c|}
\hline Variables & $\begin{array}{l}\text { Implant users } \\
(N=91), \\
\boldsymbol{n}(\%) \text { or mean }(\mathrm{SD})\end{array}$ & $\begin{array}{l}\text { Implant removers } \\
(N=61) \\
n(\%) \text { or mean }(\mathrm{SD})\end{array}$ & $p$-value \\
\hline \multicolumn{4}{|l|}{ Province } \\
\hline Gauteng & $63(69)$ & $30(49)$ & - \\
\hline North West & $28(31)$ & $31(51)$ & 0.01 \\
\hline Age (years), mean (SD) & $30(6)$ & $30(6)$ & 0.35 \\
\hline Born in South Africa & $73(81)$ & $48(79)$ & 0.71 \\
\hline \multicolumn{4}{|l|}{ Home language } \\
\hline Setswana & $19(20)$ & $25(41)$ & - \\
\hline isiZulu & $26(29)$ & $7(11)$ & - \\
\hline isiXhosa & $10(11)$ & $7(11)$ & - \\
\hline English & $5(5)$ & $3(5)$ & - \\
\hline Other & $31(34)$ & $31(19)$ & 0.04 \\
\hline Employed & $56(62)$ & $33(54)$ & 0.32 \\
\hline \multicolumn{4}{|l|}{ Household income, ZAR (USD) } \\
\hline Unknown & $21(26)$ & $11(19)$ & - \\
\hline$<5000(357)$ & $39(48)$ & $28(49)$ & - \\
\hline $5000-9999(357-714)$ & $18(22)$ & $14(25)$ & - \\
\hline $10000-30000(714-2142)$ & $4(5)$ & $4(7)$ & 0.81 \\
\hline \multicolumn{4}{|c|}{ Highest level of education completed } \\
\hline Primary & $5(6)$ & $4(7)$ & - \\
\hline Secondary & $59(66)$ & $41(67)$ & - \\
\hline Post-school qualification & $26(29)$ & $16(26)$ & 0.92 \\
\hline Currently in sexual relationship & $72(80)$ & $54(92)$ & 0.06 \\
\hline \multicolumn{4}{|l|}{ Current relationship status ${ }^{*}$} \\
\hline Married & $20(22)$ & $21(34)$ & - \\
\hline Stable partner & $28(31)$ & $25(41)$ & - \\
\hline Casual partners & $8(9)$ & $4(7)$ & - \\
\hline Single & $34(38)$ & $11(18)$ & 0.05 \\
\hline Lives with partner & $20(22)$ & $28(46)$ & 0.002 \\
\hline \multicolumn{4}{|l|}{ Other contraceptives ever used ${ }^{\dagger}$} \\
\hline DMPA & $50(55)$ & $29(48)$ & 0.37 \\
\hline NET-EN & $21(23)$ & $16(26)$ & 0.60 \\
\hline Oral pill & $30(33)$ & $35(57)$ & 0.003 \\
\hline Intrauterine device & $1(1)$ & $1(2)$ & 0.77 \\
\hline Male condoms & $51(56)$ & $43(70)$ & 0.07 \\
\hline Female condoms & $9(10)$ & $8(13)$ & 0.54 \\
\hline Female sterilisation & $1(1)$ & $1(2)$ & 0.77 \\
\hline
\end{tabular}

( $p=0.19$ ). Not surprisingly, therefore, some were concerned about the method's efficacy: 'I just want to know whether is there any chance to conceive if you were using implant.' Conversely, a few women were worried about how long it would take for fertility to return after removal, if at all: 'I just want to know if I will be able to conceive again.' Only $34 \%$ of users and $23 \%$ of removers answered in the affirmative to the question: 'Do you know how the implant works to prevent pregnancy?' $(p=0.12)$.

When asked what additional information they require, women mostly wondered about how side-effects should be managed and why specific effects occur. One woman wanted to have a better understanding of the 'body's reaction to it [the implant]', and another was concerned about whether 'the side-effects [can] damage anything in my body'. Many women also wondered why only some had experienced side-effects and not others, with one asking: 'Why do other people react badly and I haven't even had a single side-effect?' Among both users and removers, only $57 \%$ of users and $52 \%$ of removers reported having been informed about side-effects of the implant at the time of insertion.

Three women wanted more information about potential drug interactions with the implant, especially about the combined use of the implant and antiretroviral drugs. One woman wished to know where to go for removal, and another asked how this would actually be done.

\section{Overall perspectives of women on the implant}

When asked to rate their overall experience with the implant, $74 \%$ of current users classified their experience as having been 'good' or 'very good', and the large majority felt the implant was superior to other methods. For example, $68 \%$ of users felt the implant was superior to injectable contraception. By contrast, $69 \%$ of removers viewed their 
Table 2. Initiation of the implant, duration of use and overall experiences with the method, comparing women currently using the implant and those who have removed the device

\begin{tabular}{|c|c|c|c|c|}
\hline Variable category & Variable & $\begin{array}{l}\text { Implant users } \\
(N=91), \\
n(\%) \text { or } \\
\text { median (IQR) }\end{array}$ & $\begin{array}{l}\text { Implant } \\
\text { removers } \\
(N=61), n(\%) \text { or } \\
\text { median }(\mathrm{IQR})\end{array}$ & $p$-value \\
\hline \multirow{9}{*}{$\begin{array}{l}\text { Initial source of information about } \\
\text { the implant }\end{array}$} & Friend & $27(30)$ & $18(30)$ & - \\
\hline & Family member & $11(12)$ & $9(15)$ & - \\
\hline & Other implant user & $12(13)$ & $6(10)$ & - \\
\hline & Clients at facility & $6(7)$ & $7(11)$ & - \\
\hline & Provider at facility & $27(30)$ & $15(25)$ & - \\
\hline & School & $1(1)$ & $2(3)$ & - \\
\hline & Pamphlets or posters at clinics & $0(0)$ & $3(5)$ & - \\
\hline & Television & $3(3)$ & $0(0)$ & - \\
\hline & Internet & $2(2)$ & $0(0)$ & 0.30 \\
\hline \multirow{4}{*}{$\begin{array}{l}\text { Discussed implant use with partner before } \\
\text { insertion }^{*}\end{array}$} & No, but knows it's inserted & $13(16)$ & $13(24)$ & - \\
\hline & No, does not know it's inserted & $27(34)$ & $7(13)$ & - \\
\hline & Yes, talked and agreed & $37(47)$ & $35(64)$ & - \\
\hline & Yes, talked and did not agree & $2(3)$ & $0(0)$ & 0.02 \\
\hline \multirow[t]{2}{*}{ Request for implant } & User initiated & $80(90)$ & $53(91)$ & - \\
\hline & Nurse initiated & $9(10)$ & $5(9)$ & 0.76 \\
\hline \multirow[t]{8}{*}{ Reasons method was initiated } & Saves time and fewer clinic visits ${ }^{\dagger}$ & $29(32)$ & $22(37)$ & - \\
\hline & Longer duration of protection ${ }^{\dagger}$ & $14(16)$ & $18(30)$ & - \\
\hline & For effective pregnancy prevention & $10(11)$ & $2(3)$ & - \\
\hline & Better than other methods & $7(8)$ & $3(5)$ & - \\
\hline & Recommended at facility & $6(7)$ & $5(8)$ & - \\
\hline & Information from others & $6(7)$ & $3(5)$ & - \\
\hline & Does not want more children & $6(7)$ & $1(2)$ & - \\
\hline & Other & $12(13)$ & $5(8)$ & 0.19 \\
\hline \multirow[t]{7}{*}{ Information provided at initiation } & Effectiveness of implant & $27(29)$ & $12(20)$ & 0.19 \\
\hline & How long implant can be used for & $61(67)$ & $40(66)$ & 0.85 \\
\hline & When to return for removal & $46(51)$ & $34(56)$ & 0.53 \\
\hline & Safety & $37(41)$ & $12(20)$ & 0.007 \\
\hline & Side-effects & $52(57)$ & $32(52)$ & 0.57 \\
\hline & How to know implant is in place & $16(18)$ & $6(10)$ & 0.18 \\
\hline & Preventing STIs & $14(15)$ & $8(13)$ & 0.70 \\
\hline \multirow[t]{2}{*}{ Knowledge level } & Believes she knows how implant works & $31(34)$ & $14(23)$ & 0.12 \\
\hline & Knows to remove implant after 3 years & $90(99)$ & $60(100)$ & 0.42 \\
\hline \multirow[t]{2}{*}{ Duration used } & Months, median (IQR) & $24(12-28)$ & $8(6-12)$ & - \\
\hline & Range & $0.3-36$ & $2-24$ & $<0.001$ \\
\hline \multirow{6}{*}{$\begin{array}{l}\text { Implant considered a better method } \\
\text { than other options }\end{array}$} & Injectables & $62(68)$ & $8(13)$ & $<0.001$ \\
\hline & Oral pill & $64(70)$ & $12(20)$ & $<0.001$ \\
\hline & IUD & $36(40)$ & $10(17)$ & 0.002 \\
\hline & Male condoms & $56(63)$ & $10(16)$ & $<0.001$ \\
\hline & Female condoms & $44(49)$ & $11(19)$ & $<0.001$ \\
\hline & Female sterilisation & $34(38)$ & $12(20)$ & 0.017 \\
\hline \multirow{5}{*}{$\begin{array}{l}\text { Rating of overall experience with } \\
\text { the implant }\end{array}$} & Very good & $30(33)$ & $1(2)$ & - \\
\hline & Good & $37(41)$ & $8(13)$ & - \\
\hline & Average & $11(12)$ & $10(16)$ & - \\
\hline & $\mathrm{Bad}$ & $9(10)$ & $27(44)$ & - \\
\hline & Very bad & $4(4)$ & $15(25)$ & $<0.001$ \\
\hline \multicolumn{5}{|c|}{$\begin{array}{l}\text { STIs = sexually transmitted infections; IQR = interquartile range; IUD = intrauterine device. } \\
{ }^{*} \text { Among those who had a partner at the time. } \\
{ }^{+} \text {Saves time, fewer clinic visits and longer duration of protection were considered indicators of method convenience. } \\
{ }^{*} \text { Multiple-response question. }\end{array}$} \\
\hline
\end{tabular}

experience with the method as having been 'bad' or 'very bad'. Still, some $15 \%$ of removers felt their experience had been 'good', and a similar proportion believed that the implant was better than oral contraception and injectable methods.
In describing their experiences with the implant, users mainly commented on the method's convenience, mirroring the motives that had underlain their initial decision to use it. A 25-year-old described this as: 'I don't have to worry about coming to the clinic to collect 
pills', with another saying 'I don't have to stress about being in long queues waiting to get prevention pills, so I only come once and be stressfree for 3 years.' The effectiveness of the implant was also praised by some, especially by one woman who had previously had an unintended pregnancy while using DMPA. Another, a 21-year-old, spoke of how the contraceptive had allayed her anxiety about pregnancy: 'Since I've started using it I am not worried about getting pregnant.' Some enthusiasts suggested the method was especially suitable for younger women, with one woman saying: 'I think if they can go to school and introduce it for teenage pregnancy, because it takes time to expire and I haven't experienced side-effects.'

\section{Side-effects among users and removers}

In free-text responses, many users stated categorically that they had not experienced any side-effects. One woman summed this up well: 'For me, I haven't experienced any side-effect unlike before using Depo, this one it is very good to me', and another concurred: 'I haven't had a problem, not even one, everything is just normal.' Ten of the users, however, reported having had heavy bleeding, with one saying: 'Although I experienced constantly bleeding, I would say it is not that bad.' A similar number (13/91) of users ascribed headaches to implant use. One said, for example, 'I would say it's a good preventive method I have ever used, but I experience a headache on early days when I inserted it, but now I'm ok and I would like to continue using it'. These sentiments were echoed by another woman: 'I sometimes bleed and experience bad headache, but it disappear at times and it doesn't bother my health.'

When asked about reasons for discontinuation, the vast majority of removers cited intolerable side-effects (90\%). Two-thirds of these related to changed bleeding patterns, which were described as follows: 'I was bleeding a lot, non-stop', or 'I was having periods every day' and 'the bleeding I had, it was uncontrollable for 3 months.' As this quote and several others suggest, women found not only the duration of bleeding problematic, but also the amount: $31 \%$ of removers said they had experienced heavy bleeding.

Approximately a third (13/37) of the women who had had the implant removed for heavy or prolonged bleeding had sought advice from healthcare providers, and been given oral contraception for bleeding control. Though the medication had controlled bleeding for brief periods of time in some women, none reported that it provided long-term symptom relief. A few indicated that considerable gaps between bleeding intervals were also problematic, with one saying: 'I haven't experienced something bad, except I don't see my periods now.'

Headaches were given as the reason for $44 \%$ of the removals related to side-effects. These were described as 'constant headaches' and 'headaches every day'. One woman said: 'It was fine in the beginning, but then as the months went by it [the implant] started to cause me severe migraines.' Weight gain, often linked to an increased appetite, accounted for $15 \%$ of removals, but weight loss was also mentioned by a few women.

Some women had multiple side-effects, which occurred in various combinations, for example: 'Since I inserted it, I always had bleeding and terrible headache', and 'because of heavy bleeding [my] sexual desires drop, it makes me sick, nausea, headaches and I will never use it again.' Others reported generalised or nonspecific complaints, such as 'I was always sick and I felt tired every time', and another woman attributed human emotions to the device: 'Because it [the implant] doesn't like me'.

Many side-effects were described as having diminished with time. One woman explained that 'I was bleeding in the beginning after a month that I had inserted it, but then it stop and I have been fine ever since.' For some, however, the occurrence of side-effects did not recede, nor were they confined to the period shortly after insertion. For example, one woman who had used the device for 26 months reported that 'At first it was fine, but now I'm experiencing headache, bleeding and I'm also gaining weight, so I want to remove it now', and another recounted that 'At first 2 years using implant I had a good experience, but now I am bleeding a lot and I want to remove it'.

Complications at the site of insertion were reported by four women (three users and one remover). This included ongoing pain in the arm ('a painful elbow on the side where implant was inserted') and a rash ('[I] recently develop some rash near the implant'). One woman reported that ' $[\mathrm{My}]$ arm was swollen, black and painful'.

Lastly, three women had the implant removed as they wished to conceive, while one woman removed the implant after using it for 2 years as she had become pregnant while using it. She then had an elective abortion and had an IUD inserted thereafter.

\section{Effects of rumours and provider attitudes}

The attitudes of others, including partners, family and community members, towards the implant had shaped the way that women perceived the method and their decision about whether to continue its use. A quote from a remover illustrates this well: 'I didn't think it [headaches almost every day] was a problem, until I heard other women who have inserted it complain about the same thing.' In keeping with this theme, several doubts about the implant were apparent, mainly concerning the effectiveness of the method: 'I would like to know why you get pregnant while on it? I heard some rumours', and 'Is it true that you can fall pregnant while using it, because other sister told me that you can fall pregnant?'

Rumours that appear to exaggerate the frequency and severity of side-effects were also commonly reported: 'Why does it affect people so badly? I heard there are lot of side-effects', and 'So many people are complaining about side-effects, can't the health people do something to make it better?' One woman summed this up well: '[The] perception is that most, or the large majority of women experience side-effects, even women who had not had any side-effects had the perception that most women had them.'

Several women were worried about potential drug interactions with the implant, but lacked detailed information, as illustrated by the question: 'Is it true that if you are on chronic treatment is not good to use implant?' In fact, three women reported concerns about potential interactions with antiretroviral drugs, an HIV-positive woman saying: 'And I didn't have any complications, except for later I was told that I could get pregnant when using the Implanon while on ARVs [antiretrovirals]. So I had to remove it.' Another said: 'Now as I'm going to start the ARVs programme the sister who is going to initiate me with it said I must remove the implant because of the sideeffect.' Finally, it is possible that negative connotations associated with the method had already reduced access to the implant. One woman asked: 'Why they are not inserting implant anymore at the clinic? They refer us to other facility, my sister wanted to insert it.' Another woman reported difficulties in accessing removal services, saying that 'I came to remove it, but they told me the nurse who was inserting it is not around ... they refer me to [clinic X] and at [clinic X] they refused, they said I must go to a clinic where I inserted.'

\section{The influence of male partners and sexual relationships}

The influence of partners on implant insertion and removal varied considerably by partner type. Of those in a relationship, levels of partner consultation and agreement prior to insertion were higher among married $(82 \%, 32 / 39)$ than unmarried women $(42 \%, 40 / 95$; $p<0.001)$. Partner involvement was also higher among removers $(64 \%)$ than users $(47 \% ; p=0.02)$. Interestingly, a third of users were 
using the method without the knowledge of their partner (33\%, $27 / 81$ ), while only $13 \%$ of removers had informed their partner of implant use $(7 / 55 ; p=0.06)$. One user explained this practice: 'My partner wants more children and he doesn't want me to use preventive method, so I thought implant would be good to hide that I'm on contraceptive.'

A number of women recounted how the implant had affected their sexual relationships. This mostly related to prolonged bleeding, with one woman in a stable relationship saying: 'Because I was bleeding almost every day, so I couldn't have sex with him because it felt uncomfortable, and another noting that 'We couldn't have sex anymore because I was always bleeding.' Partners held strong views on bleeding side-effects, with one woman with a stable partner saying: 'He was starting to get irritated by the fact that I was always sick and obviously we couldn't have sex on a regular basis.' One woman even said: 'It was okay, but then my boyfriend told me to go and remove it.'

A few women reported that the implant had negatively affected their libido, with one saying: 'I had excessive bleeding, headaches and I didn't feel my boyfriend sexually' Vaginal dryness was also noted: 'My vagina was always dry so it was hard for me to sleep with my husband.' Lastly, men appear to have also contributed to propagating misconceptions or rumours about the implant. One woman recalled that he [her stable partner] told me that people are saying it stops women from having children and that one day I would [be like] those women that struggle to have children'.

\section{Discussion}

This study, the first evaluation of the implant introduction in SA, provides important insights into why women chose the method, their experiences with it and their reasons for discontinuation. Examining differences in the characteristic of users and removers, and the reasons underpinning their very divergent experiences, provides useful insights for improving implant services, especially pre-insertion counselling and management of side-effects. The findings about side-effects may appear concerning, but are similar to studies of removers elsewhere, ${ }^{[12]}$ as are the high levels of acceptability among users, who commonly make up about $80 \%$ of all those who insert the implant. ${ }^{[13-16]}$

The motivations for implant use were strongly tied to the method's convenience, such as its long action and lack of requirement for adherence by the user. Reductions in clinic visits were especially important for women working or studying. Interestingly, convenience was more commonly cited as the motive for use in removers than users. Perhaps, if convenience is overwhelming the primary motive rather than factors such as contraceptive effectiveness, then women more readily remove it once 'inconvenient' effects become apparent. Women with motives such as contraceptive effectiveness appear to be more resilient in tolerating difficulties encountered.

Rumours, based on partially accurate information, appear to have accrued rapidly, despite many women being very satisfied with the method. Both users and removers recalled how they, other women and healthcare providers had held very favourable views towards the implant when it was first introduced, but that these opinions are being eroded by negative perceptions around side-effects and even of a lack of efficacy in preventing pregnancy. These perceptions may become entrenched within popular culture unless they are redressed soon.

While interactions with providers are clearly important, the influence of family and community in shaping women's attitudes to contraceptive methods should not be underestimated. These groups - who were commonly the initial, but also ongoing source of information about the method - may promote a certain method, but can also rapidly undermine its use. It is promising that many women had negotiated implant use with their partners, the majority of whom apparently supported implant use, at least initially. Other women, however, had elected to use the device clandestinely. Men reportedly exerted influence over removals, especially where prolonged bleeding had affected sexual relations.

The large majority $(50 / 61,82 \%)$ of removers had discontinued the implant within a year of insertion. As is consistent with studies elsewhere, ${ }^{[13,17]}$ the principal reasons for implant removal were sideeffects, specifically intolerable bleeding for two-thirds of removers and headaches in almost a half. Users and removers often appeared to have similar side-effects. More nuanced qualitative data are needed to understand why some women elect to remove the implant, while it is retained by others with seemingly identical effects. Relationship status and sexual activity may explain this, at least in part. Removals were especially common among married or cohabiting women. In a long-term intimate relationship, the inconvenience of prolonged bleeding may be felt more than in a situation where a woman is single or in a casual relationship. This consideration, which has not been reported in several similar previous studies, ${ }^{[3,14]}$ should perhaps be discussed with women prior to their selection of the implant.

The topics covered in pre-insertion counselling appear to vary widely and require standardisation. Heightened emphasis on the considerable strengths of the implant may promote its uptake and continuation (only a quarter (29\% users, and $29 \%$ removers) recalled being informed of the method's remarkable effectiveness, for example. Aside from some reduction in effectiveness due to drug interactions with some drugs, the implant is as much as 180 times more effective than short-acting methods. ${ }^{[18]}$ Even though efavirenz use reduces the effectiveness of the implant, by lowering levels of the active drug in Implanon (etonogestrel), ${ }^{[19,20]}$ the implant still appears more effective in these patients than other contraceptive methods. Relative effectiveness - as well as the likelihood of side-effects - can be hard to convey in counselling. ${ }^{[21]}$ Job aids may facilitate this, but some recommend simply discussing contraceptive options in order of effectiveness from highest (LARCs) to lowest. ${ }^{[2,23]}$ This 'LARC-first' approach to counselling extends, in some settings, to LARCs being promoted explicitly as first-line contraception and other methods as second-tier. ${ }^{[23]}$

In the absence of pre-insertion counselling preparing women for sideeffects, these may be particularly alarming, leading to implant removal in some who otherwise may have retained it. Support, both clinical and psychosocial, is required when side-effects occur. ${ }^{[24]}$ This would include providing medication to mitigate abnormal bleeding and headaches. Although women only 'need' to return every 3 years, they should be encouraged to attend the clinic for assistance, reassurance and support as needed. Counsellors had strongly emphasised the notion that the device 'needs to' or 'should' be used for 3 years, rather than it 'could' be. Emphasis on the former may needlessly discourage uptake among women desiring protection for shorter periods.

Providers require a clear policy on interactions between the implant and enzyme-inducing drugs, including certain ARVs. ${ }^{[20,25]}$ In the presence of ambiguity, providers may understandably err on the side of caution, either by not offering implants to potentially eligible women, or through unnecessarily recommending implant removal. ${ }^{[20]}$

The groups commonly targeted by implant programmes, such as young women, first-time contraceptive users and women immediately postpartum or post-abortion, ${ }^{[26,27]}$ do not appear to have been specifically prioritised in SA. Only $15 \%$ of participants were aged 18 - 24, the group in SA in which almost a third have an unmet 
need for contraception, according to national surveys. ${ }^{[5,6]}$ Low levels of HIV testing among the participants also reinforces long-standing calls for the integration of HIV and contraception services. ${ }^{[28]}$

The study has several limitations. Owing largely to deficiencies in record-keeping, only $20 \%$ of potentially eligible women were enrolled. Also, there are some notable gaps in our data. For example, we did not enquire whether women had experienced difficulties with accessing implant removal. The inclusion of many open-ended questions, however, allowed us to explore the data in more detail than would have been possible with a quantitative approach alone. Lastly, the diversity of the study population is a strength of the study. Views were gathered of women from many clinics, across both a densely urbanised and a semi-rural district.

\section{Conclusions}

While favourable views towards the implant initially drove its uptake, negative perceptions may now risk undermining these gains. Media campaigns, including visual and social media and patient materials addressing rumours or misinformation about the method, are required to reshape the negative discourse around the method. Implant services need to focus on counselling regarding the method's advantages, especially its high effectiveness and women's rapid return to fertility after discontinuation, attributes seemingly not highlighted during counselling. But, equally importantly, much greater attention during pre-insertion counselling is needed to ensure that women are aware of potential side-effects, particularly bleeding changes, enabling potential users to make an informed decision about whether the implant is the right method for them. Standardised counselling tools could assist providers to explain the complexities around the relative effectiveness of contraceptives, and side-effects. Treatment protocols could guide providers on clinical care for women experiencing side-effects, especially bleeding and headaches. Moreover, more efforts are needed to promote the implant among young women, those employed or studying, as well as firsttime contraceptive users. All these actions together could reverse the persistent decline in implant use in SA.

Acknowledgments. We thank the Department of Health for allowing us access to the health facilities, the anonymous reviewers of this article and the clinics that participated. We also would like to acknowledge the data collectors, Fortunate Gombela, Iris Sishi, Lindiwe Mbuyisa, Ntombenhle Twala, Siziwe Sidabuka and Tebogo Mokoena.

Author contributions. DP was the project lead, and was responsible for the project design, implementation and write-up and was supported by $\mathrm{CM}$, MP, OAA, NN and SM. MFC largely supported data analysis and write-up and HR is the senior author providing oversight and review.

Funding. Funding was received from the United Nations Population Fund (UNFPA), which also provided technical assistance.

Conflicts of interest. None.
1. Jacobstein R, Stanley H. Contraceptive implants: Providing better choice to meet growing family planning demand. Glob Health Sci Pract 2013;1(1):11-77. https://doi.org/10.9745/GHSP-D-12-00003

2. Blumenthal P, Voedisch A, Gemzell-Danielsson K. Strategies to prevent unintended pregnancy: Increasing use of long-acting reversible contraception. Hum Reprod Update 2011;17(1):121-137. https:// doi.org/10.1093/humupd/dmq026

3. Dickerson LM, Diaz VA, Jordon J, et al. Satisfaction, early removal, and side effects associated with longacting reversible contraception. Fam Med 2013;45(10):701-707.

4. Duvall S, Thurston S, Weinberger M, Nuccio O, Fuchs-Montgomery N. Scaling up delivery of Duvall S, Thurston S, Weinberger M, Nuccio O, Fuchs-Montgomery N. Scaling up delivery of
contraceptive implants in sub-Saharan Africa: Operational experiences of Marie Stopes International. contraceptive implants in sub-Saharan Africa: Operational experiences of Marie

5. Chersich MF, Wabiri N, Risher K, et al. Contraception coverage and methods used among women in Couth Africa: A national household survey. S Afr Medi J 2017;107(4):307-314. https://doi.org/10.7196/
Sold South Africa: A national
SAMJ.2017.v107i4.12141

6. National Department of Health, Statistics South Africa (StatsSA), South African Medical Research Council National Department of Health, Statistics South Africa (StatsSA), South African Medical Research Counci,
Inner City Fund. South Africa Demographic and Health Survey 2016: Key Indicators: StatsSA, 2017. http:// www.statssa.gov.za/publications/Report\%2003-00-09/Report\%2003-00-092016.pdf (accessed 15 September 2017)

7. World Health Organization. Expanding Family Planning Options: Contraceptive Introduction Reconsidered: A review and conceptual framework. Geneva: WHO, 1994. http://apps.who.int/iris/ bitstream/10665/58660/1/WHO_HRP_ITT_94.1.pdf (accessed 15 September 2017).

8. Lince-Deroche N, Pleaner M, Morroni C, et al. Achieving universal access to sexual and reproductive health services: The potential and pitfalls for contraceptive services in South Africa. S Afr Health Review 2016;2016(1):95-108. https://www.health-e.org.za/wp-content/uploads/2016/05/South-African-HealthReview-2016.pdf (accessed 15 September 2017).

9. Pillay D, Morroni C, Pleaner M, et al. Gaps in monitoring systems for Implanon NXT services in South Africa: An assessment of 12 facilities in two districts. S Afr Med J 2017;107(10):827-831. https://doi org/10.7196/SAMJ.2017.v107i10.12822

10. Adeagbo OA, Mullick S, Pillay D, et al. Uptake and early removals of Implanon NXT in South Africa: Perceptions and attitudes of health workers. S Afr Med J 2017;107(10):822-826. https://doi.org/10.7196 SAMJ.2017.v107i10.12821

11. Sundari Ravindran TK, Berer M, Cottingham I, World Health Organization. Beyond Acceptability: Users Perspectives on Contraception. London: Reproductive Health Matters, 1997. http://apps.who.int/iris/ bitstream/10665/42012/1/0953121003.pdf (accessed 15 September 2017).

12. Diedrich JT, Desai S, Zhao Q, Secura G, Madden T, Peipert JF. Association of short-term bleeding and cramping patterns with long-acting reversible contraceptive method satisfaction. Am J Obstet Gynecol cramping patterns with long-acting reversible contraceptive metho

13. Bahamondes $\mathrm{L}$, Brache V, Meirik O, et al. A 3-year multicentre randomized controlled trial of etonogestrelBahamondes $\mathrm{L}$, Brache $\mathrm{V}$, Meirik $\mathrm{O}$, et al. A 3-year multicentre randomized controlled trial of etonogestrel-
and levonorgestrel-releasing contraceptive implants, with non-randomized matched copper-intrauterine and levonorgestrel-releasing contraceptive implants, with non-randomized matched copper-
device controls. Hum Reprod 2015;30(11):2527-2538. https://doi.org/10.1093/humrep/dev221

14. Abraham M, Zhao Q, Peipert JF. Young age, nulliparity, and continuation of long-acting reversible contraceptive Abraham M, Zhao Q, Peipert JF. Young age, nulliparity, and continuation of long-acting reversible co
methods. Obstet Gynecol 2015;126(4):823-829. https://doi.org/10.1097/AOG.0000000000001036

15. Casey PM, Long ME, Marnach ML, Bury JE. Bleeding related to etonogestrel subdermal implant in a Casey PM, Long ME, Marnach ML, Bury JE. Bleeding related to etonogestrel subdermal implant in
US population. Contraception 2011;83(5):426-430. https://doi.org/10.1016/j.contraception.2010.09.012 US population. Contraception 2011;83(5):426-430. https://doi.org/10.1016/j.contraception.2010.09.012
O'Neil-Callahan M, Peipert JF, Zhao Q, Madden T, Secura G. Twenty-four-month continuation of reversible

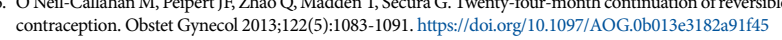
contraception. Obstet Gynecol 2013;122(5):1083-1091. https://doi.org/10.1097/AOG.0b013e3182a91445
Mutihir JT, Nyango DD. One-year experience with Implanon sub-dermal implants in Jos, Nigeria. Niger J Clin Prac 2010;13(1):28-31.

18. Darney P, Patel A, Rosen K, Shapiro LS, Kaunitz AM. Safety and efficacy of a single-rod etonogestrel implant (Implanon): Results from 11 international clinical trials. Fertil Steril 2009;91(5):1646-1653 https://doi.org/10.1016/j.fertnstert.2008.02.140

19. Chappell CA, Lamorde M, Nakalema S, et al. Efavirenz decreases etonogestrel exposure: A pharmacokinetic evaluation of implantable contraception with antiretroviral therapy. AIDS 2017;31(14):1965-1972. https://doi.org/10.1097/qad.0000000000001591

20. Patel RC, Morroni C, Scarsi KK, Sripipatana T, Kiarie J, Cohen CR. Concomitant contraceptive implant and efavirenz use in women living with HIV: Perspectives on current evidence and policy implications for family planning and HIV treatment guidelines. J Int AIDS Soc 2017;20(1):1-6. https://doi.org/10.7448/IAS.20.1.21396

21. Lopez LM, Steiner M, Grimes DA, Hilgenberg D, Schulz KF. Strategies for communicating contraceptive effectiveness. Cochrane Database Syst Rev 2013(4):CD006964. https://doi.org/10.1002/14651858. CD006964.pub3

22. Secura GM, Madden T, McNicholas C, et al. Provision of no-cost, long-acting contraception and teenage pregnancy. New Engl J Medicine 2014;371(14):1316-1323. https://doi.org/10.1056/NEJMoal400506

23. Ott MA, Sucato GS, Committee on Adolescence. Contraception for adolescents. Pediatrics 2014;134(4):e1257-e1281. https://doi.org/10.1542/peds.2014-2300

24. Mansour D, Korver T, Marintcheva-Petrova M, Fraser IS. The effects of Implanon on menstrual bleeding pattern Eur J Contracept Reprod Health Care 2008:13:Suppl 1:S13-S28. https://doi.org/10.1080/13625180801959931

Pyra

5. Pyra M, Heffron R, Mugo NR, et al. Effectiveness of hormonal contraception in HIV-infected women usin

antiretroviral therapy. AIDS 2015;29(17).2353-2359. https:// doi.org/10.1097/QAD.0000000000000827

Bryant AG, Bauer AE, Stuart GS, et al. Etonogestrel-releasing contraceptive implant for postpartum
adolescents: A randomized controlled trial. J Pediatr Adolesc Gynecol 2017;30(3):389-394. https://doi adolescents: A randomized con

27. Berlan E, Mizraji K, Bonny AE. Twelve-month discontinuation of etonogestrel implant in an outpatien pediatric setting. Contraception 2016;94(1):81-86. https://doi.org/10.1016/j.contraception.2016.02.030 28. Smit JA, Church K, Milford C, Harrison AD, Beksinska ME. Key informant perspectives on policy- and Service-level challenges and opportunities for delivering integrated sexual and reproductive health and HIV
sit care in South Africa. BMC Health Services Res 2012;12:48. https://doi.org/10.1186/1472-6963-12-48

Accepted 31 August 2017. 